\title{
Process Analysis and Reengineering based on Analytic Hierarchy Process
}

\author{
Xian-Nian CAO \\ R\&D Department \\ Lenovo Group \\ Beijing, China \\ E-mail: Caoxn@lenovo.com \\ Zhong-Wei HE \\ R\&D Department \\ Lenovo Group \\ Beijing, China \\ E-mail: hezw@lenovo.com
}

\author{
Yu-Min $\mathrm{HE}^{*}$ \\ School of Economics and Management \\ Beihang University \\ Beijing, China \\ heyumin@buaa.edu.cn
}

\begin{abstract}
Modern society is developing rapidly every day. Because market changes frequently, customer demand varies greatly. Moreover, the world economy trends globalization with the development of science and technology represented by information technology, which makes the competition among enterprises more and more intensified. Many enterprises have to make Business Process Reengineering (BPR) to adapt to new environments to obtain and sustain competitive advantage in global competition. This paper studies the BPR of Lenovo Group that is a global brand computer manufacturer and applies Analytic Hierarchy Process (AHP) and value chain analysis to the process analysis and reengineering in Lenovo Group.
\end{abstract}

Keywords- business process reengineering; analytic hierarchy process; value chain analysis

\section{INTRODUCTION}

Lenovo Group manufactures and sells reliable, high quality, secure and easy-to-use products. In order to indentify competitive advantage and chance, Lenovo Group made SWOT analysis. According to the result of the SWOT analysis, Lenovo Group not only found its advantage and opportunity but also found its disadvantage and threat. The weakness of Lenovo Group lies in its lack of strong core competitiveness, lack of innovative talents and innovation system, and lack of integration of its own R\&D with that of other brands after the mergence and acquisition of the other brands. It did not make compensation of advantage and disadvantage with the other brands acquired.

From strategic perspective, the core processes in Lenovo Group were new product development process, potential customers ordering and payment process, manufacturing process, logistics process, product management process, and after sale service process. Lenovo Group accomplished BPR of the new product development process, the manufacturing process, as well as other processes in the first four years of mergence and acquisition. However, it did not perform BPR of the product management process. The product management process had many nodes that were inter departmental. When there were problems, a lot of time and energy were needed to coordinate the various departments to solve the problems. The internal friction was very serious. Moreover, it was difficult to guarantee the accuracy of product data, leading to the bottleneck of enterprise development to a certain extent. To start BPR of the product management process is urgent and is a problem needs to be solved by the managers in Lenovo Group.

\section{ANALYTIC Hierarchy PROCESS}

AHP is created by the famous American operations research expert, Professor Saaty. The basic steps of AHP are the determination of evaluation criteria, construction of the hierarchical structure model, construction of judgment matrix, calculation of judgment matrix, test consistency, and calculation weights at each level. The judgment matrix is obtained by making pairwise comparison judgment so as to determine the weight of each criterion. The judgment matrix is illustrated in Formula (1).

$$
A=\left(a_{i j}\right)=\left(\begin{array}{cccc}
w_{1} / w_{1} & w_{1} / w_{2} & \ldots & w_{1} / w_{n} \\
w_{2} / w_{1} & w_{2} / w_{2} & \ldots & w_{2} / w_{n} \\
\ldots & \ldots & \ldots & \ldots \\
w_{n} / w_{1} & w_{n} / w_{2} & \ldots & w_{n} / w_{n}
\end{array}\right)
$$

The scale of AHP is defined as aij $=1$ if $i$ is equally important as $\mathrm{j}$, aij $=3$ if $\mathrm{i}$ is weekly more important than $\mathrm{j}$, aij $=5$ if $i$ is strongly more important than $j$, aij $=7$ if $i$ is very strongly more important than $j$, aij $=9$ if $i$ is absolutely more important than $\mathrm{j}$. If the importance is between two adjacent degrees, aij $=2,4,6,8$. If $j$ is compared with $i$, aij $=1 /$ aji. AHP requires that each judgment matrix must be computed and tested for consistency. The consistency is tested for the maximum Eigen value $\lambda_{\max }$ by the consistency test index $C I=(\lambda-n) /(n-1)$, where $\mathrm{n}$ is the 
order of the judgment matrix. If $C I<0.1$, the consistency test passes, the result can be applied.

Researchers have applied AHP to BPR and to process analysis and evaluation. For example, Selma et al. applied AHP for BPR implementation [1]. Zhang and Wang performed process analysis of collaborative management in IT outsourcing projects and proposed the collaborative mechanism based on AHP [2]. Lv and Zhu applied AHP to select core business processes for BPR [3].

\section{PROCESS ANALYSIS BASED ON AHP}

The product management process in Lenovo Group contained a lot of sub-processes. Lenovo Group decided to perform BPR and built a project team. The project team convened relevant department leaders and domain experts for discussion and analyzed these processes through workshop. The project team determined that the product management process consisted of the component management process, new product management process, configurable product list management process, whole machine test management process, configurable product list release process, specification document management process, product change management process, engineering change management process, and finished product management process, noted as $\mathrm{W} 1, \mathrm{~W} 2, \ldots, \mathrm{W} 9$, respectively.

The project team applied AHP to evaluate the subprocesses of the product management process for the selection of sub-processes for reengineering. The project team discussed and determined the evaluation criterion system through regular meeting, making the feasibility of reengineering and the degree of influence on the enterprise as the first level criteria. The first level criteria were further divided into the second level criteria. The feasibility of reengineering was divided as team role responsibility change, business rule change, and work flow change. The degree of influence was divided as financial impact, outside impact, and inside impact. The solution layer was the sub-processes of the product management process. The project team provided the questionnaire to ask the domain experts to make pairwised comparison of criteria.

The weights of the criteria were computed by AHP calculation. At the first level, the weight of the feasibility of reengineering is 0.75 and the weight of the degree of influence is 0.25 . At the second level, the weight of the team role responsibility change is 0.08 , the weight of the business rule change is 0.23 , the weight of the work flow change is 0.44 , the weight of the financial impact is 0.03 , the weight of the outside impact is 0.08 , and the weight of the inside impact is 0.15 . Table I illustrates the weights.
TABLE I. WEIGHTS OF CRITERIA

\begin{tabular}{|c|c|c|c|}
\hline $\begin{array}{c}\mathbf{1}^{\text {st }} \mathbf{L e v e l} \\
\text { Criterion }\end{array}$ & Weight & $\mathbf{2}^{\text {nd }}$ Level Criterion & Weight \\
\hline \multirow{2}{*}{$\begin{array}{c}\text { feasibility of } \\
\text { reengineering }\end{array}$} & \multirow{2}{*}{0.75} & $\begin{array}{c}\text { Team Role } \\
\text { Responsibility } \\
\text { Change }\end{array}$ & 0.08 \\
\cline { 3 - 4 } & & $\begin{array}{c}\text { Business Rule } \\
\text { Change }\end{array}$ & 0.23 \\
\cline { 3 - 4 } & & Work Flow Change & 0.44 \\
\hline \multirow{2}{*}{$\begin{array}{c}\text { degree of } \\
\text { influence }\end{array}$} & \multirow{2}{*}{0.25} & Financial Impact & 0.03 \\
\cline { 3 - 4 } & & Outside Impact & 0.08 \\
\cline { 3 - 4 } & & Inside Impart & 0.15 \\
\hline
\end{tabular}

The domain experts were also asked to evaluate subprocesses. They made pairwise comparison of each subprocess according to $2^{\text {nd }}$ level criteria. The averages of the evaluation scores for $2^{\text {nd }}$ level criteria are illustrated in Table II. The weighted scores of the sub-processes can be obtained from the evaluation. The component management process is 1.83 , new product management process is 0.24 , configurable product list management process is 0.98 , whole machine test management process is 0.21 , configurable product list release process is 0.47 , specification document management process is 0.20 , product change management process is 0.50 , engineering change management process is 0.49 , and finished product management process is 1.08 . Based on these, the processes needed to be reengineered are the component management process, configurable product list management process, and finished product management process.

TABLE II. AVERAGE SCORES OF SUB-PROCESSES

\begin{tabular}{|c|c|c|c|c|c|c|}
\hline $\begin{array}{c}\text { Sub } \\
- \\
\text { pro } \\
\text { cess }\end{array}$ & $\begin{array}{c}\text { Team } \\
\text { Role } \\
\text { Respon } \\
\text { sibility } \\
\text { Chang } \\
\mathbf{e}\end{array}$ & $\begin{array}{c}\text { Business } \\
\text { Rule } \\
\text { Change }\end{array}$ & $\begin{array}{c}\text { Work } \\
\text { Flow } \\
\text { Chang } \\
\mathbf{e}\end{array}$ & $\begin{array}{c}\text { Finance } \\
\text { Impact }\end{array}$ & $\begin{array}{c}\text { Outside } \\
\text { Impact }\end{array}$ & $\begin{array}{c}\text { Inside } \\
\text { Impart }\end{array}$ \\
\hline W1 & 1.875 & 1.857 & 1.813 & 1.818 & 1.857 & 1.809 \\
\hline W2 & 0.234 & 0.232 & 0.237 & 0.234 & 0.232 & 0.237 \\
\hline W3 & 0.972 & 0.964 & 0.99 & 0.972 & 0.964 & 0.99 \\
\hline W4 & 0.207 & 0.205 & 0.224 & 0.207 & 0.205 & 0.21 \\
\hline W5 & 0.47 & 0.467 & 0.476 & 0.47 & 0.467 & 0.476 \\
\hline W6 & 0.193 & 0.191 & 0.196 & 0.206 & 0.191 & 0.196 \\
\hline W7 & 0.498 & 0.521 & 0.504 & 0.498 & 0.467 & 0.504 \\
\hline W8 & 0.47 & 0.494 & 0.476 & 0.498 & 0.494 & 0.504 \\
\hline W9 & 1.082 & 1.068 & 1.084 & 1.082 & 1.068 & 1.084 \\
\hline
\end{tabular}

\section{Process Reengineering Based on Value Chain} ANALYSIS

From the perspective of value chain analysis, enterprise activities can be divided into value-added and non-valueadded activities [4]. The value-added activities can be divided into basic activities and auxiliary activities. Basic activities are the activities around products, which include product development, purchase, production, delivery, sale, after-sale service, etc. Auxiliary activities are the support for basic activities, which include enterprise hardware 
infrastructure implementation, human resources management, etc.

The project team applied value chain analysis and reengineered the component management process, configurable product list management process, and finished product management process. For the sub-processes to be reengineered, the process diagnosis was carried out through the value analysis of activities to determine whether an activity was a value-added activity or a non-value-added activity. Cost analysis was also carried out at the same time. Non-value-added and unnecessary activities were eliminated. Low-cost activities were reserved. High-value but high-cost activities were analyzed deeply and adjusted to increase the capability to create value.

The following describes the reengineering of the component management process as an example. The

Component management process before reengineering was very simple, only two steps. Many communication links were off line as Figure 1 illustrated. The component engineer needed to communicate with the purchasing and even the financial department to submit relevant information to the data center. The version management was missing and the quality could not be traced and controlled. The component management process involved several main stages: application submission, procurement maintenance, manufacturing maintenance, financial maintenance i.e. cost maintenance.

Figure 1. Component management process before reengineering.

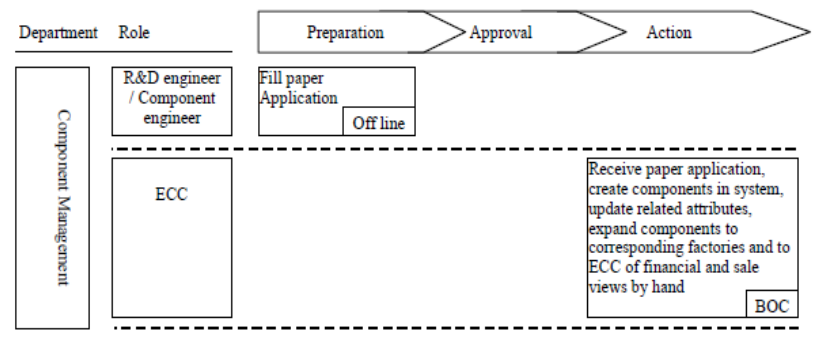

The project team applied value chain analysis to the component management process. They considered procurement maintenance and manufacturing maintenance were value-added processes, and reserved while component application was in the PLM system. Component cost information was automatically transmitted from the financial cost prediction system to the data center by information system integration. Figure 2 illustrates the component management process after reengineering.
Figure 2. Component management process after reengineering.

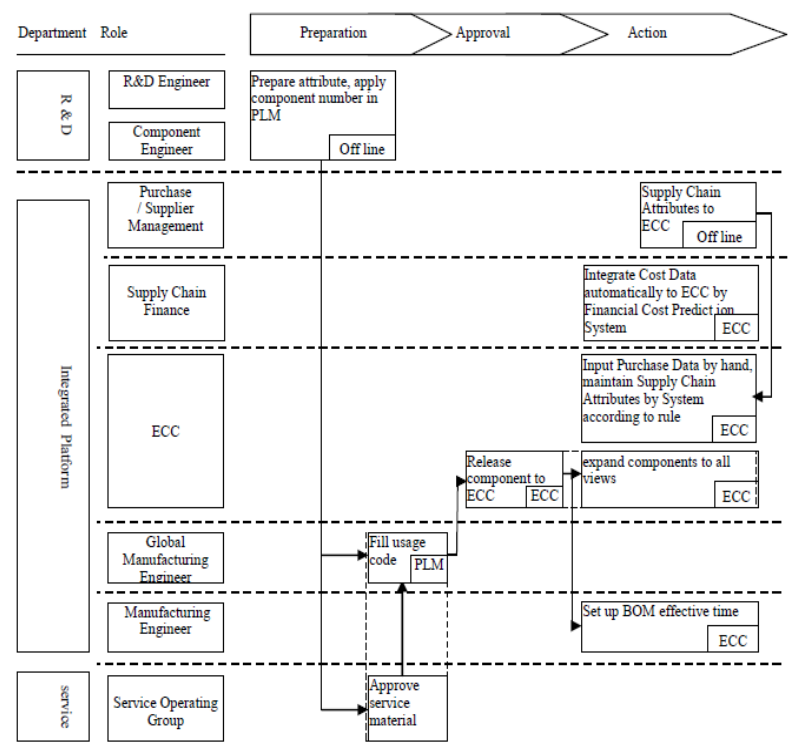

\section{RESUlt OF PROCESS REENGINEERING}

Through process reengineering, Lenovo Group standardized the product management process, greatly improved data flow and product quality, and reduced cost. For a cycle of half year, the quality ratio of the component management process was improved. Table III illustrates quality ratios of the component management process. The quality ratio before reengineering was 80.2. The quality ratio after reengineering was 90.3 . The quality rate of the component management process was improved by $13.6 \%$. After the reengineering of the CTO BOM management process, product planning and prediction could be carried out at the SBB level, which improved the flexibility and accuracy of planning and forecasting. Table IV illustrates the operating costs of the finished product management process before and after reengineering, the total operating cost before reengineering was 840.28 million yuan with operating cost of ordered MTM 335.35 million yuan and the other operating cost 504.92 million yuan. The total operating cost after reengineering was 461.41 million yuan with operating cost of ordered MTM 337.22 million yuan and the other operating cost 124.19 million yuan. The cost saving was 380.73 million yuan.

TABLE III. COMPARISON FOR COMPONENT MANAGEMENT PROCESS

\begin{tabular}{|c|c|c|c|c|c|}
\hline Time & $\begin{array}{c}\text { MTM } \\
\text { Quant. } \\
\text { (unit) }\end{array}$ & $\begin{array}{c}\text { Ordered } \\
\text { MTM } \\
\text { Quant. } \\
\text { (unit) }\end{array}$ & $\begin{array}{c}\text { Total } \\
\text { Operat } \\
\text {. Cost } \\
\text { (m.y.) }\end{array}$ & $\begin{array}{c}\text { Operat. } \\
\text { Cost of } \\
\text { Ordered } \\
\text { MTM } \\
\text { (m.y.) }\end{array}$ & $\begin{array}{c}\text { Other } \\
\text { Operat } \\
\text {. Cost } \\
\text { (m.y.) }\end{array}$ \\
\hline $\begin{array}{c}\text { Before } \\
\text { Reeng. }\end{array}$ & 70023 & 27946 & 840.28 & 335.35 & 504.92 \\
\hline $\begin{array}{c}\text { After } \\
\text { Reeng. }\end{array}$ & 38451 & 28102 & 461.41 & 337.22 & 124.19 \\
\hline
\end{tabular}

TABLE IV. COMPARISON FOR FINISHED PRODUCT MANAGEMENT PROCESS 


\begin{tabular}{|c|c|c|c|}
\hline Time & $\begin{array}{c}\text { Component } \\
\text { Quantity } \\
\text { (unit) }\end{array}$ & $\begin{array}{c}\text { Modified } \\
\text { Quantity } \\
\text { (unit) }\end{array}$ & $\begin{array}{c}\text { Quality } \\
\text { Ratio } \\
\text { (\%) }\end{array}$ \\
\hline $\begin{array}{c}\text { Before } \\
\text { Reengineering }\end{array}$ & 26220 & 5200 & 80.2 \\
\hline $\begin{array}{c}\text { After } \\
\text { Reengineering }\end{array}$ & 25970 & 1603 & 93.8 \\
\hline
\end{tabular}

In summary, Lenovo Group reduced cost, improved quality, and achieved good results in the reengineering of the product management process. The experience and the method adopted by Lenovo Group could provide reference for the BPR of the enterprises in growth.

\section{ACKNOWLEDGMENT}

The authors would like to thank the people in Lenova Group for their participation on the reengineering of the production management process.

\section{REFERENCES}

[1] S. L. Mansar, H. A. Reijers, F. Ounnar, "Development of a decisionmaking strategy to improve the efficiency of BPR," Expert Systems with Applications, vol. 36, 2009, pp. 3248-3262.

[2] H. Zhang, W. Wang, "process analysis of collaborative management in IT outsourcing project," Journal of Harbin University of Commerce, vol. 1, 2011, pp. 44-47.
[3] W. Lv, Y. Zhu, "The Application of the Analytic Hierarchy Process in Business Process Reengineering Preferring," Forest Engineering, vol. 29, 2013, pp. 142-145.

[4] E. Qi , H. Wang, "Business process reengineering based on value chain," Industrial Engineering Journal, vol. 8, Jan. 2005, pp. 58-60. 